\title{
Method of remote dynamic thermographic testing of wind turbine blades
}

by S.I.Melnyk*, I.G.Tuluzov** and A.S.Melnyk**

* Kharkov National University of RadioElectronics, Lenin Ave.14, 61166, Kharkov, Ukraine, smelnyk@yandex.ru

** Kharkov Regional Centre for Investment, of.405, Tobolska str.12, 61072, Kharkov, Ukraine

\begin{abstract}
Quality testing of rotor blades of wind power stations requires labor-intensive dismantling operations and work on high altitude. At the same time, the capabilities of modern thermal imagers allow performing the thermography of rotor blades from the ground level without stopping their operation. Moreover, periodic loads occurring in the process of blade rotation cause its heating, sufficient for registration using a thermal imager. At the same time, defective areas are characterized by specific dynamics of heat flows. We have constructed a numerical model of occurrence of overheating in defective rotor blades. The method of thermography of blade surface in the process of supervision from the ground level and the algorithm of processing of results is proposed. It has been shown that the sensitivity of the proposed method allows revealing characteristic defects of rotor blades.
\end{abstract}

\section{Introduction}

In the process of the development of wind power engineering a tendency of increasing of generator capacity and rotor blade size is observed. It results in the increasing role of quality routine inspection of the technical condition of rotor blades. At the same time, the operations of dismantling and re-installation of rotor blades become increasingly expensive and labor-intensive. In this connection the demand is increasing for passive remote testing methods allowing routine inspection of rotor blade condition without their stopping and dismantling.

In our opinion the most suitable method for this purpose is the thermography, which is becoming as efficient as other methods in terms of accuracy and sensitivity. The principal advantage of this method is the possibility of performing testing from the ground level without stopping the blade rotation. At the same time, the high-quality optical system of modern thermal imagers and their performance allow achieving a level of accuracy sufficient for revealing most characteristic defects of rotor blades. In the present paper a method of such testing is proposed and the analysis of its capabilities is represented.

\section{Capabilities of thermographic methods of rotor blade testing}

Preliminary experimental research of active and passive testing of rotor blades using the thermographic methods [1] has proven their high efficiency. It appears that the heating cause by both periodic (as a result of rotation) and incidental (wind gust) loads on rotor blade is sufficient for creating a temperature difference significantly exceeding the threshold of sensitivity of a thermal imager. These results are reproduced in laboratory conditions in the process of testing the rotor blades using the vibration thermal method.

At the same time, it should be noted that a number of factors complicate the accurate and reliable thermal testing in case of performing the blade monitoring from the ground level. Currently, attempts are made in order to solve these problems using a number of technical improvements:

- $\quad$ Special lifters for platform with operator and monitoring equipment.

- Devices of active thermal exposure.

- Use of expensive stand methods for testing and monitoring, etc.

In this connection, the method is remote dynamic thermal testing is becoming a promising trend. The sensitivity of a modern thermal imager exceeds $0.02 \mathrm{~K}$. The possibility of using telescopic objective with focal distance of $200 \mathrm{~mm}$ allows achieving an angular resolution of at least 0.1 millirad. For the distance of $100 \mathrm{~m}$ (thermal imaging of rotating blades from the ground level) it provides a resolution of approximately $1 \mathrm{~cm}^{2}$ per pixel. In this case an area or $6 \times 5 \mathrm{~m}^{2}$ is covered, allowing thermography of rotating blade surface in dynamic mode. The thermal features of thermograms are to a large degree smoothed by the effect of heat spreading from local inhomogeneities. For increasing the resolution capability of the method the processing of thermal images using the previously developed PDTT (projection dynamic thermal tomography) method is required [2].

\section{Description of the method of remote dynamic thermographic testing of rotor blades}

In the table 1 below the factors limiting the capabilities of remote passive thermal testing of rotor blades are listed. In the second column our propositions based on our many year's experience of operation and implementation of thermal testing technologies are represented. The third column represents the estimated results of their implementation.

On the basis of the performed research the method and software for thermographic testing of rotor blades of wind power generators from the ground level, allowing to perform thermal imaging express testing of the mechanical state of blades of wind power generators and reveal defects like cracks, lamination, water accumulation and defects of integrity from the ground level in the process of operation. 
Table 1. The factors limiting the capabilities of remote passive thermal testing of rotor blades

\begin{tabular}{|c|c|c|}
\hline Problematic factors & Proposed methods of their elimination & Estimated results \\
\hline $\begin{array}{l}\text { Defocusing of image in case of } \\
\text { incidental variation of distance to the } \\
\text { rotor blade }\end{array}$ & $\begin{array}{l}\text { In case of imaging from the ground level } \\
\text { from the distance of approximately } 100 \mathrm{~m} \\
\text { oscillations are inessential }\end{array}$ & Stable sharp thermal image \\
\hline $\begin{array}{l}\text { Exposure to sunlight and } \\
\text { dependence of visible thermal } \\
\text { brightness on the angle of view } \\
\text { distort the thermal imaging of rotor } \\
\text { blade surface }\end{array}$ & $\begin{array}{l}\text { 1. Special algorithm of processing of } \\
\text { thermal images in serial images allow } \\
\text { filtration of these artefacts (know-how) } \\
\text { 2. Method of stereo imaging of the } \\
\text { thermal map of rotor blade surface in } \\
\text { case of using two synchronized thermal } \\
\text { imagers. }\end{array}$ & $\begin{array}{l}\text { 1. Filtration of overexposure and } \\
\text { artifacts of surface curvature of } \\
\text { the thermal image } \\
\text { 2. 3D image of the thermal map of } \\
\text { rotor blade surface for the } \\
\text { selected frames of the thermal } \\
\text { image. }\end{array}$ \\
\hline $\begin{array}{l}\text { Blurring of image in the process of } \\
\text { blade rotation }\end{array}$ & $\begin{array}{l}\text { Algorithm of reverse convolution allows } \\
\text { restoring un-blurred image with high } \\
\text { accuracy }\end{array}$ & $\begin{array}{l}\text { Restored un-blurred image in the } \\
\text { whole thermal image }\end{array}$ \\
\hline $\begin{array}{l}\text { Inhomogeneity of the emission } \\
\text { coefficient (spot) of the blade surface } \\
\text { creates artefacts in the thermogram }\end{array}$ & $\begin{array}{l}\text { Method of dynamic thermal tomography } \\
\text { allows filtering these artefacts (know- } \\
\text { how). Repeated imaging of the blade in } \\
\text { several phases of rotation is required. }\end{array}$ & $\begin{array}{l}\text { Reconstruction of the chart of } \\
\text { emissivity coefficient on the blade } \\
\text { surface and restoring of valid } \\
\text { temperature values. }\end{array}$ \\
\hline $\begin{array}{l}\text { Cooling-down of rotor blade in } \\
\text { nighttime and heating in the morning } \\
\text { create thermal flows distorting the } \\
\text { map of thermal emission } \\
\text { characterizing the present defects }\end{array}$ & $\begin{array}{l}\text { Registration of these flows using the } \\
\text { specially-developed thermal physical } \\
\text { model (know-how) allows taking account } \\
\text { of these flows and increasing the self- } \\
\text { descriptiveness of defect testing }\end{array}$ & $\begin{array}{l}\text { Increase of sensitivity of the } \\
\text { method by one order of magnitude } \\
\text { (amplitude of the useful signal } \\
\text { from the defect after processing of } \\
\text { the thermal image). }\end{array}$ \\
\hline $\begin{array}{l}\text { Individual structural features of } \\
\text { blades, not related to presence of } \\
\text { defects, create hardly-distinguished } \\
\text { artefacts in the thermograms }\end{array}$ & $\begin{array}{l}\text { Creation of database of thermal physical } \\
\text { charts of blades allowing to trace the } \\
\text { changes and use a differential method of } \\
\text { testing }\end{array}$ & $\begin{array}{l}\text { In perspective, calculation of } \\
\text { blade lifetime and estimation of } \\
\text { development of micro defects in it } \\
\text { will be possible }\end{array}$ \\
\hline
\end{tabular}

Special features of the proposed method:

- Use of natural heating of rotor blade, caused by both periodic (rotation) and incidental (wind gust) loads.

- Use of repeated scheme of blade imaging in several phases of rotation.

- Creation of database of thermal physical charts of blades and tracing of change of blade condition.

- $\quad$ Possibility of using two synchronized thermal imagers.

- Use of algorithm of restoring blurred thermal images.

- Use of the method of dynamic thermal tomography for revealing and visualization of hidden defects.

The process of testing does not require:

- $\quad$ Lifting of the platform with operators and testing equipment on high altitude

- $\quad$ Equipment for active thermal exposure of ground testing of rotor blades

- Expensive stand methods in special-purpose laboratories
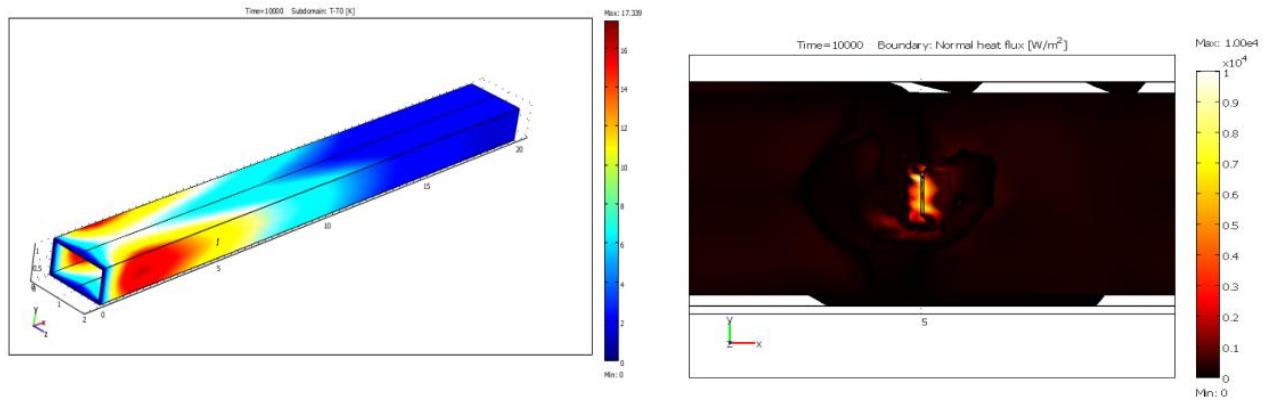

Testing is performed by a single operator. Processing of results of thermal imaging is performed using the specially-developed computer program. Approbation of the method has been performed on a computer model of a rotating rotor blade (Fig.1).

Fig. 1. A) Temperature distribution on the surface of a computer model of the blade, under the influence of periodic load B) The heat flux on the surface of the model induced by a transverse crack

\section{REFERENCES}

[1] Meinlschmidt P., Aderhold J. "Thermographic Inspection of Rotor Blades" ECNDT 2006 - Tu.1.5.3

[2] Melnyk S. I., Melnyk S. S. and Tuluzov I. G. "Method of projection dynamic thermal tomography (PDTT)"QIRT2012-308, Archives QIRT 2012 